Estudios Fronterizos, vol. 10, núm. 19, enero-junio 2009, pp. 9-48

\title{
Familia, remesas y redes sociales en torno a la migración en Veracruz central
}

\author{
Ana Lid del Ángel Pérez* \\ Andrés Rebolledo Martínez*
}

Resumen. Se realizó investigación de campo durante 2005 y 2006 en Veracruz Central, México. Se trabajó con 38 familias de migrantes indocumentados y cinco varones que han retornado a las localidades. El objetivo fue analizar los factores detonantes de la migración en cuatro localidades, el papel que desempeñan diversas redes sociales en el fenómeno, y la dinámica familiar a raíz de la ausencia del varón o proveedor económico. Los resultados mostraron como detonantes de la migración la búsqueda de mejores oportunidades de empleos y calidad de vida, fundamentada en una modificación de la ética de trabajo y expectativas que no pueden obtener en México, y donde diversos tipos de redes facilitan la salida de los migrantes, la estancia en los Estados Unidos y la búsqueda de empleo. Se encontró la continuidad y el reforzamiento de la estructura y dinámica de los grupos domésticos extensos, y la prevalencia de los roles patrilineales jerárquicos, donde las mujeres mantienen el papel doméstico tradicional, sin independencia económica y bajo la tutela económica y moral de la parentela del varón ausente. Con relación al uso de las remesas, la voluntad del varón es ejecutada por medio de sus parientes, por lo anterior, se conservan los tradicionales papeles de un tipo de matrimonio a distancia, fundamentado en la no co-residencia.

Palabras clave: migración, patrilineal, familia, modelo, reproducción, remesas.

Abstract. Field research was conducted during 2005 and 2006 in central Veracruz, Mexico. We worked with 38 families of undocumented migrants and five men who have returned to the localities. The objective was to analyze the factors detonating of migration in four locations, as well as the role played by diverse social networks in the phenomenon, and family dynamics as a result of the absence of male or economic provider. The results showed as triggers of migration seeking better opportunities for jobs and quality of life, based on a modification of the work ethic and expectations that can not get in Mexico, and where various types of networks facilitate the departure of migrants, stay in the United States, and job search. There was continuity and strengthening the structure and dynamics of extended domestic groups, and the prevalence of patrilineal hierarchical roles, where women, maintain the traditional domestic role, without economic independence, under the tutelage economic and moral advancement of the kindred male absent. With regard to the use of remittances, the will of man is executed through their relatives, while retaining the traditional roles of a type of marriage at a distance, not based on the co-residence.

Keywords: migration, patrilineal, family, model, reproduction, remittances.

*Investigadores titulares del Instituto Nacional de Investigaciones Forestales, Agrícolas y Pecuarias, INIFAP, Veracruz. Correo electrónico: aldap28@yahoo.com 


\section{Introducción}

La migración internacional constituye un fenómeno global cuyos factores se fundamentan en la dinámica económica de los países de origen, así como en la de los receptores. Villa y Martínez (2000:15) y Hatton y Williamson (2003) han señalado que la base económica de la migración internacional es la distribución desigual de oportunidades laborales, ingresos y condiciones materiales de vida entre los países, la cual opera en el plano de la oferta de mano de obra en los países receptores, motivada por la innovación tecnológica y el impulso de las condiciones de competitividad, que inciden en la atracción migratoria. En los países de origen, la migración aparece cuando las condiciones de inestabilidad económica no generan las opciones suficientes para la reproducción mínima de los grupos familiares (Leiken, 2000).

Debido a su importancia, la migración internacional ha sido analizada enfatizando los flujos migratorios, así como el incremento del volumen de las remesas y el impacto que ocasiona al interior de los grupos familiares. Binford (2002:19) indica que la migración de México a los Estados Unidos se incrementó de una base cero a 30 y $50 \%$ en un periodo de 15 a 20 años a partir de la crisis de los ochenta, y muestra también la afectación económica de la crisis de esa década, así como su efecto en los hogares y en los estados y municipios mexicanos que contienen procesos de migración internacional, además de que las remesas equivalen a la tercera parte de las transferencias federales. Autores como Santiago (2001:43) y Carral (2005) han señalado que en 1994 México ocupaba a escala mundial el segundo lugar en recepción de remesas después de la India, y el primero en América Latina y el Caribe, con un monto aproximado de 16 mil millones de dólares; los mismos autores sostienen que los envíos de los migrantes a sus familias son considerados una fuente de divisas que al transferirse al país son registradas en la balanza de pagos en el rubro de remesas y su importancia ha ido en ascenso, representando un poco más del $2.7 \%$ del Producto Interno Bruto (PIB), por lo que actúan como factor de equilibrio en la balanza de pagos al permitir una mayor liquidez financiera.

La dinámica de los ingresos por remesas familiares muestra que mientras en el periodo 1995-2000 éstas crecieron a una tasa promedio anual de 
11.2\%, en el lapso 2001-2003 lo hicieron en 26.8\%; este dato refleja una mayor cobertura contable de esas operaciones y un comportamiento al alza de tales flujos, pues durante 2003 el monto total de las remesas familiares fue de 10031 millones de dólares durante los primeros nueve meses del año, mientras que en 2004 se contabilizaron 12419 dólares, equivalentes al $81 \%$ del total del valor de las exportaciones del petróleo crudo (Banco Nacional de México, 2004:4).

El crecimiento de las remesas y su efecto en las localidades de origen de los migrantes, así como el continuo crecimiento de oleadas migratorias a los Estados Unidos, ha orientado el análisis de los factores detonantes de la migración hacia la importancia e impacto de las remesas y la perpetuación del fenómeno en diversos estados de la República Mexicana, así como hacia las entidades emergentes donde hasta hace poco sus habitantes no se incorporaban a corrientes de migración internacional (Córdova, 2002; Tuirán, 2002; Maloney y Grusenmeyer, 2005; Maloney, 2006).

Dentro de las entidades federativas emergentes que contribuyen con población migrante a Estados Unidos, Veracruz ha pasado del lugar número 27, en 1997, al cuarto en 2002, calculándose entre 400 mil y 800 mil personas en esta situación, de donde el centro de Veracruz contribuye con más de 19\% del total (Córdova, 2002:21); asimismo, de acuerdo con cifras de Tuirán (2002), alrededor de 900 localidades del estado observan un flujo migratorio hacia los Estados Unidos, aunque el fenómeno es particularmente significativo en 220 localidades. El Consejo Nacional de Población (Conapo, 2005), estimó que del total de migrantes en el país, $96.47 \%$ se dirigió a los Estados Unidos, representando para Veracruz una tasa similar a la nacional; además, se calculó que $4.88 \%$ que asumió el estado sobre el total de migrantes que se dirigieron a Estados Unidos, fue equivalente a 76587 veracruzanos, y que éstos, a su vez, equivalían al 1.1\% del total de la población de la entidad en el año 2000; lo anterior representó $0.8 \%$ del estimado oficial de residentes mexicanos en Estados Unidos, y 21.8\% del estimado de traslados anuales de mexicanos al mismo país; los datos anteriores son para un periodo de cinco años (1995 a 2000).

De la misma manera, las cifras del Banco Nacional de México (BdeM, 2004:14) indican que la magnitud de las remesas para Veracruz en 
2004 fue de 704 millones de pesos, lo cual muestra la importancia que el fenómeno ha adquirido. El Conapo (2005) también enfatizó que de acuerdo con los datos de la Oficina de Estadísticas Laborales de Estados Unidos, entre 1998 y 2008 se podría acumular en aquel país un excedente de hasta cinco millones de empleos sin trabajadores para ocuparlos, al tiempo que cerca de $57 \%$ de los empleos creados requeriría de personal con un modesto entrenamiento y una educación formal por debajo del nivel de preparatoria.

Sin embargo, Córdova (2002) estima que aunque la migración en México ha sido asociada a factores de orden económico, como la falta de oportunidades en los espacios rurales y la deficiencia en la aplicación de políticas de desarrollo estatales, y aunque es indudable su importancia como detonador del proceso, la reproducción misma de esta práctica engendra transformaciones en todos los niveles y dimensiones de la vida social, de tal manera que reviste características socioculturales y no solamente económicas; por lo anterior, este autor reconoce que la migración asume nuevas causas en su proceso de gestación y cuestiona la capacidad explicativa de los factores económicos como la causa única y constante. De la misma manera, Hurtado (2003) y García (2004:7) argumentan que aunque la migración tiene como objetivo primordial factores económicos, intervienen en ella variables no económicas como la búsqueda de alternativas de superación y desarrollo personal o familiar en otros mercados laborales.

Específicamente y con relación al ámbito familiar, diversos autores y organizaciones como Domínguez (1999:3,4 ), la Comisión Económica para América Latina y el Caribe (Cepal, 2001), y Jiménez y Costa (2006) han señalado que los aspectos de cambio demográfico y socioeconómico producidos en el mundo donde la migración tiene un papel importante, han influido en las modalidades de la vida familiar, provocando cambios en su composición y estructura, resaltando que la salida de un miembro del grupo familiar, específicamente del varón, ocasiona un desequilibrio y constituye una fuente de tensión y desintegración familiar que ha contribuido a aumentar las responsabilidades con que se enfrentan las mujeres; por su parte, Falicov (2001:35) argumenta que la migración ocasiona la emergencia de nuevas formas de familias: familias fragmentadas que sufren ventajas y 
desventajas tanto para aquellos miembros del grupo doméstico que se queda en el país de origen, como para los que salen.

Por lo anterior, el objetivo de la investigación efectuada fue analizar los factores detonantes del flujo migratorio y el papel de las redes sociales en el fenómeno, así como el impacto ocasionado por la salida de uno de los varones en el funcionamiento y la dinámica del grupo familiar, en cuatro localidades de Veracruz Central.

\section{Metodología}

El trabajo presenta un análisis sobre la emergencia de Veracruz como entidad expulsora de migrantes a los Estados Unidos, donde se combina material de orden etnográfico y teórico. El análisis se orienta a los detonantes de la migración, el papel de las remesas, así como el impacto del fenómeno en el ámbito de la estructura familiar de los grupos domésticos, en hogares donde el proveedor económico o uno de ellos ha emigrado, destacando la importancia de diversas redes que facilitan

la salida del país, así como la entrada a los Estados Unidos y el acceso a empleos. La información se obtuvo de tres tipos de actores: familias de migrantes indocumentados, migrantes que han retornado y empleadores de migrantes veracruzanos en los Estados Unidos.

La investigación se realizó en Veracruz Central, México, durante 2005, en las comunidades de Vargas, municipio de Veracruz, Acazónica y Angostillo, municipio de Paso de Ovejas, Hatillo, municipio de La Antigua. Se trabajó con 38 grupos familiares donde uno de los varones había emigrado a los Estados Unidos en calidad de indocumentado. El $60 \%$ de ellos pertenece al municipio de Paso de Ovejas y el resto a Veracruz. La cantidad de casos estudiados tiene como fundamento un seguimiento efectuado a familias de migrantes internacionales de las localidades donde el fenómeno es cada vez más fuerte. La selección de las localidades se debe al hecho de albergar poblaciones que poseen pequeñas parcelas en propiedad o ejidales, en las que sus estrategias de sobrevivencia incluyen la ganadería bovina y/o el cultivo de maíz, mango y papaya, combinadas tradicionalmente con el trabajo asalariado en el corredor industrial de Veracruz o en otro tipo de empleos urbanos; es decir, gente que aunque tiene pequeños 
predios y empleos fijos o estacionales (Del Ángel y Mendoza, 2002), ha considerado la migración internacional como una estrategia más, es decir, una alternativa a los empleos locales, lo cual es una muestra representativa de la dinámica regional de Veracruz Central.

Por otra parte, durante dos años consecutivos (2006 y 2007) se estableció contacto con grupos de empresarios del estado de Nueva York que ocupan a veracruzanos indocumentados y realizan giras a Veracruz; los empresarios están insertos en un programa dirigido por la Universidad de Cornell que busca afianzar o estabilizar a los trabajadores en sus empleos, usando como estrategia el mejoramiento de las condiciones de vida de los migrantes y el mayor contacto cultural entre empleados y empleadores; en este caso el objetivo de la gira fue visitar a las familias de los migrantes para que los empresarios conozcan y convivan con la familia de los trabajadores, como una manera de empatizar con ellos y con los motivos que tuvieron para abandonar sus localidades, arriesgar su integridad física, enfrentar lo desconocido y dejar la seguridad de sus hogares. La meta final del programa es retener de forma indefinida o por mayor tiempo a los trabajadores; lo anterior se debe a que por un lado observan una constante movilidad de empleo y lugar, y por otro son reconocidos como excelentes trabajadores. El programa reconoce la necesidad de sensibilizar a los empleadores y convertirlos en portavoces de humanización en el trato, libre de discriminación, resaltando la importancia económica de su trabajo, medido en el valor económico de las actividades que realizan (Maloney y Grusenmeyer, 2005; Maloney, 2006).

La información cuantitativa que se presenta fue obtenida por medio de una cédula de encuesta aplicada a miembros de los grupos familiares donde el varón o jefe de familia, entendido como el proveedor económico, ha migrado a los Estados Unidos y la jefatura doméstica está conferida a las esposas, padres o hermanos varones de los migrantes. Las cédulas de encuesta fueron dirigidas a las personas que de alguna manera detentan la jefatura en ausencia del jefe de familia, y se aplicaron los sábados por la tarde y los domingos, días que comúnmente se encuentran en el hogar. De esta manera se obtuvo información de tres tipos: datos personales de los entrevistados (es- 
posas o padres de los migrantes), datos del migrante e información del funcionamiento de los hogares. Cabe aclarar que además de la cédula de encuesta se aplicaron entrevistas a los actores arriba señalados con objeto de profundizar en temas como la composición o dinámica de la estructura familiar antes y después de que el varón saliera del país, así como información sobre ocupaciones y vínculos de los miembros del grupo doméstico antes y después de la partida del varón, así como los nuevos arreglos posteriores a la partida.

El análisis se orientó a los grupos domésticos, entendidos como un grupo familiar, el cual tiene dos modalidades: nuclear (padre, madre e hijos) y extenso, que en sí mismos marcan diferentes fases de un ciclo doméstico; en este caso se analizan los grupos domésticos extensos con una residencia en común o separada y actividades compartidas por sus miembros relacionadas con la producción y el consumo y cuya finalidad es asegurar la reproducción y continuidad del grupo donde la herencia, los patrones residenciales y la jerarquía son ejecutados a través de la línea del varón (patrilineales), a los que Robichaux (1997) denominó "sistema familiar mesoamericano". El grupo familiar extenso es aquel formado por varios tipos de parientes que incluyen dos o más generaciones, representando una etapa avanzada del ciclo doméstico en el que los hijos han formado su familia pero han establecido su residencia en casa del padre y son parte de un grupo de familia extendida, donde hay ciertos lazos de cooperación y/o reciprocidad (Del Ángel y Mendoza, 2002). En este sentido se analizan los grupos familiares del varón, debido a que son los que tienen conferida la tutela económica y moral de la esposa e hijos en ausencia del jefe de familia, así como la administración de las remesas. También se recurre al concepto de dinámica intrafamiliar, entendido éste como el conjunto de relaciones de cooperación, intercambio, poder y conflicto que hombres, mujeres y generaciones establecen en el seno familiar, y en torno a la división del trabajo y de los procesos de toma de decisiones, de acuerdo a De Oliveira et al. (1999:230).

La información fue enriquecida con entrevistas a seis migrantes que han retornado a sus hogares con objeto de retomar sus percepciones sobre diversos aspectos de la migración, resaltando razones de salida y retorno, papel de las redes sociales y situación familiar. 


\section{Resultados y discusión}

\section{Detonantes de la migración}

La modificación de las políticas económicas en México a mediados de la década de los ochenta y la inserción de este país en el proceso de globalización de la economía mundial orientaron las estrategias oficiales hacia una reestructuración productiva y tecnológica, favoreciendo las importaciones y generando también medidas para reestructurar la participación del Estado en la economía (García, 2004:4-12). El proceso de apertura comercial y de privatización de las empresas paraestatales llevado a cabo entre 1988 y 1993 ocasionó ajustes de personal y el surgimiento de miles de pequeñas empresas y microempresas, originándose una disminución del personal ocupado en promedio por empresa, que pasó de $13.7 \%$ en 1988 a $7.4 \%$ en 1993 y $6.5 \%$ en 1998, mientras el desmantelamiento de las políticas públicas de apoyo hacia los diversos sectores productivos, redefiniendo y disminuyendo el apoyo directo a las actividades agropecuarias, originó una creciente incapacidad para generar empleos e intensificó los flujos migratorios (Córdova, 2002, García, 2004:4). En Veracruz, alrededor de un millón de personas económicamente activas se encontraban desempleadas en 1996 como efecto de la apertura comercial y las políticas públicas; sumado a lo anterior, la falta de sostenibilidad en la agricultura trajo consigo una crisis en la producción de cultivos industriales como la caña de azúcar y el café afectando fuertemente a la zona central veracruzana (Plan Veracruzano de Desarrollo, 1999-2004). Los problemas financieros de las industrias nacionales de azúcar, su falta de competitividad y el incremento de la demanda de productos sustitutos, afectaron de manera importante a la economía estatal, produciendo inestabilidad en la producción, el empleo y en los salarios recibidos.

La información obtenida en entrevistas a varones en los grupos familiares mostró dos estrategias fundamentales para la sobrevivencia en la zona costera de Veracruz Central, una de ellas fundamentada en la producción de caña dependiente de los ingenios azucareros, la cual representa la fuente de ingresos más importante para una gran masa de dueños de pequeños predios. Las siembras se efectúan mediante 
convenios de producción o contratos, la interacción de los productores con los ingenios es prácticamente a través de una situación de asalariados, pero con ello se aseguran insumos, tecnología y el acceso a la comercialización, y se obtienen además prestaciones como servicio médico, préstamos en efectivo e ingresos más elevados comparados con cualquier otro cultivo. La otra estrategia es la combinación de las actividades agropecuarias con el trabajo asalariado en la ciudad industrial de Veracruz, o diversos empleos en la zona urbana, incluyendo la portuaria. Específicamente, empresas como TAMSA (Tubos de Acero de México) mantienen a la población rural aledaña como parte de su reserva laboral. Sobre este punto las familias entrevistadas señalaron que cuando alguno de los varones logra obtener un empleo, la calidad de vida del grupo familiar se eleva y su capacidad adquisitiva se hace superior a la de aquellos que dependen económicamente sólo de las actividades agropecuarias, o de algún otro tipo de trabajo asalariado; ello se debe a que la percepción salarial, aunque medida en salarios mínimos, incluye varias prestaciones que incrementan el ingreso neto, tales como premios por puntualidad y asistencia, jornadas en días festivos y reparto de utilidades. Sin embargo, cuando las empresas efectuaron ajustes de la tecnología y de personal la oferta laboral se redujo así como las oportunidades de complementar ingresos, lo que impactó negativamente en la calidad de vida de las comunidades que dependían de ellas.

Por lo anterior, actualmente la producción de caña y el trabajo industrial no representan una vía fácil o segura de obtención de ingresos para las nuevas generaciones, ya que, por una parte, la disminuida capacidad de los ingenios para expandirse y, por otra, la contracción del mercado laboral (no solamente industrial) no permiten a las nuevas generaciones reproducir las mismas estrategias de sobrevivencia de manera sostenible, esto debido a que las actividades agropecuarias son poco rentables y el trabajo asalariado es eventual, por lo que la migración aparece como una opción para satisfacer necesidades y expectativas que van más allá de lo económico. De cierta manera, las opiniones muestran una dudosa sostenibilidad no sólo de la economía local y sus actividades, sino también de los ecosistemas naturales regionales que las soportan. Resultados similares fueron encontrados 
por Lewis (2005:23-27) entre migrantes oaxaqueños productores de café orgánico, donde la falta de sostenibilidad económica de la producción y las pocas oportunidades en empleos bien remunerados incrementaron las olas de migración a los Estados Unidos.

La información cuantitativa arrojada por las encuestas sobre las actividades que realizaban los migrantes en México antes de partir, mostró que la mayoría contaba con terrenos de carácter ejidal o privados, con un promedio de 8.0 ha; en ellos se cultiva maíz, papaya y/o mango, o son usados para la ganadería; por su parte, alrededor de un tercio percibía ingresos por trabajo asalariado en la zona industrial u otro tipo de empleo, incluso por cuenta propia (carpintero, comerciante, sastre, etcétera), y únicamente el $5 \%$ estaban desempleados (cuadro 1).

Al preguntar en las localidades de estudio acerca de las causas de la migración, las respuestas indicaron como la principal el desempleo (50\%), y aunque éste parecía ser la razón dominante, la información de las mismas encuestas (cuadro 1) muestra que dentro del grupo de migrantes, solamente el $5 \%$ estaba realmente en esa situación, sobre todo considerando a aquellos que son dueños de predios, además de los que tenían empleo. Para el caso de los que tenían empleo en la zona industrial, se argumentó que no contaban con empleos fijos; el resto mencionó recibir salarios muy bajos, tener condiciones de trabajo precarias y largas jornadas sin prestaciones. En ambos casos los sistemas de contratación no ofrecían una seguridad económica o social continua para casos de enfermedad o protección

Cuadro 1. Actividades desarrolladas en porcentaje (\%) de migrantes, antes de partir y en el lugar de destino.

Veracruz, México, 2007

\begin{tabular}{lccc}
\hline Actividad laboral & México & Actividad laboral & EU. UU. \\
\hline Campesino & 58 & Agricultura & 5 \\
Empleado & 34 & Empleos (servicios) & 91 \\
Ama de casa & 3 & Doméstico & 3 \\
Desempleado & 5 & & \\
\hline
\end{tabular}

Fuente: Trabajo de campo. 
por vejez. Al orientar el cuestionamiento a expectativas en la migración, las respuestas fueron: la búsqueda de mejores oportunidades $(21 \%)$, por los bajos salarios $(21 \%)$, y para satisfacer un deseo de aventura $(8 \%)$.

Las expectativas de encontrar mejores oportunidades explica el hecho de que la mayor parte de los migrantes, incluyendo aquellos que antes de partir desempeñaban actividades agropecuarias, se orientaran a obtener empleos diferentes a sus actividades rutinarias en México; de esta manera, se encontró que la mayor parte de ellos labora en el área de servicios (55\%), efectuando diferentes tipos de actividades en restaurantes, transportes y como ayudantes de oficina; $39 \%$ en diferentes empleos urbanos, y solamente $5 \%$ tiene actividades rurales, que, sin embargo, implican menor esfuerzo comparado con el desarrollado en México, además de mayor salario.

Además, en aquellos que se fueron sólo por interés de conocer otros lugares, los familiares dijeron que detrás de este deseo de aventura estaba la búsqueda de lograr mejores condiciones de vida, con menos esfuerzo, y que Estados Unidos ofrecía esta oportunidad, sobre todo porque los parientes o "amistades" que han regresado comentan que las condiciones de trabajo son diferentes, las jornadas son concertadas y el trabajo no es tan duro como en México, aparte se gana más y se vive mejor, la vida es más fácil y los hombres pueden vivir solos pues las labores domésticas se facilitan al estar los aparatos electrodomésticos al alcance de todos.

Por otra parte, estudios sobre migrantes realizados en Ecuador por Herrera $(2001: 89,90)$ y Goycoechea y Ramírez (2002:6) señalan que la racionalidad económica no constituye una razón suficiente para explicar la migración, pero que un hecho concreto es que hay espacios de oportunidad reales que atraen y sostienen económicamente la corriente de migrantes hacia los Estados Unidos; sin embargo, también señalan la importancia de analizar la producción de significados alrededor de la experiencia migratoria como uno de los factores que definen la decisión individual de migrar, y que tiene que ver con las expectativas creadas a partir de los relatos de amigos o por las fotografías de un conjunto de representaciones sociales simbólicas sobre potencialidades laborales, éxito y progreso personal en los Estados 
Unidos. Esto en contraste con la imagen del espacio local como un mundo en crisis y con pocas oportunidades para el triunfo y para la realización de proyectos de vida.

Maloney $(2006: 2,25)$, en una encuesta aplicada a trabajadores indocumentados, en su mayoría mexicanos $(75 \%)$ y principalmente veracruzanos, para 60 lecherías de 17 condados del estado de Nueva York, obtuvo diversas razones de migración a los Estados Unidos; las respuestas mostraron que $52 \%$ dijo que fueron convencidos por pláticas con sus amigos así como por la familia, estableciendo estos argumentos como la razón primaria para emigrar; mientras, $24 \%$ dijo que fueron atraídos por ofrecimientos concretos, y $15 \%$ buscaba mejores condiciones de trabajo. De la misma manera, Martin (2003:5), en su análisis sobre migración de mexicanos a Los Ángeles, señaló dentro de los detonantes de la migración a factores económicos como empleos estacionales y precarios de los migrantes en México, y como factores no económicos destacó condiciones donde algunos de los migrantes buscan a sus parientes que están al otro lado de la frontera, pero también los deseos de aventura.

La información obtenida en el trabajo de campo coincide con los datos de Maloney $(2006,2007)$, que indican que los detonantes de migración señalados por los entrevistados muestran que las razones económicas son insuficientes para explicar las decisiones de migrar y en algunos casos no se puede hablar de pobreza extrema como la razón primordial; asimismo se observa la importancia de una mezcla de logro personal con remuneraciones justas, por lo que se puede decir que el factor económico sigue siendo crucial pero no determinante.

Los varones entrevistados señalaron que el trabajo agropecuario es muy demandante de tiempo además de agotador, y el esfuerzo no es compensado por los bajos ingresos; en el caso específico de aquellos que aun teniendo empleo emigraron, señalaron que desarrollaban jornadas laborales superiores a las ocho horas, requisito fundamental para conservar un empleo poco satisfactorio sin posibilidades de mejoramiento. Datos de Maloney (2006) indican que sus entrevistados dijeron obtener más ingresos en una hora de trabajo en los Estados Unidos, que en un día de trabajo en México, laborando en promedio 62 horas por semana con la idea de maximizar sus ingresos 
y enviar más a su hogar, pero realizando actividades con cierta especialización como ordeña, limpieza de los establos, preparación de raciones de alimentación de los animales, aplicación de tratamientos para enfermedades, inseminación de vaquillas, etcétera. La información proporcionada por Maloney $(2006: 18,19)$ muestra un panorama de trabajo agropecuario desarrollado por los indocumentados con menor grado de dificultad (cría de ganado) que el que se lleva a cabo en México, donde el rústico manejo y el poco uso de tecnología demandan mayor cantidad de esfuerzo o inversión de mano de obra; en este caso el mismo autor señaló que el promedio de horas laboradas por semana es de 62, lo que indica largas jornadas, pero precisamente las condiciones de trabajo lo permiten, debido a que son especializadas y además son voluntarias, ya que los trabajadores que alargan su horario de trabajo tienen como objetivo ahorrar o enviar más dinero a México para acortar su estancia en los Estados Unidos.

La información obtenida en las encuestas y entrevistas aplicadas en Veracruz Central, y con relación a las razones para emigrar, muestra que una de estas razones es la interrupción de una práctica cultural generalizada en el medio rural (el sistema de herencia), que favorecía patrilinealmente a los varones (véase Robichaux, 2002), donde el tamaño actual de las parcelas han agotado las posibilidades de heredar terrenos a todos los hijos hombres y a las nuevas generaciones. El sistema de herencia favorece a alguno de los hijos varones que sucede al padre - en el mejor de los casos puede favorecer a dos varones o más y en caso de no haber varones a las hijas - ; de esta forma, el resto de los hijos tiene que buscar el sustento en el trabajo asalariado agrícola o urbano.

Así, la tierra es un factor clave de permanencia o continuidad de los patrones residenciales y de reproducción económica y social, y como señala Córdova (2003), es a la vez signo y referente de un conjunto de nexos sociales que va mucho más allá de un mero valor económico. La falta de terrenos para distribuir entre los hombres jóvenes que desean crear su propia familia o la acaban de formar, ha determinado que la mayor parte de los migrantes sean varones jóvenes; esta información ayuda a explicar que la población analizada de migrantes esté compuesta principalmente de varones jóvenes (95\%), con edades de entre 22 a 47 años, con un promedio de 31 años; cifras similares 
encontró Maloney (2005:2), pues en sus resultados $84 \%$ de los indocumentados contaba con 30 años o menos.

En términos prácticos, y respecto a la migración, la juventud ofrece mejores posibilidades de alcanzar el destino, ya que la fortaleza física es prioritaria para cruzar la frontera, para huir de las patrullas fronterizas y caminar grandes distancias, además, el mercado laboral ofrece mayores oportunidades para los varones jóvenes. Como característica importante de la zona de estudio, cabe señalar que el patrón migratorio aunque es de varones principalmente, ha incorporando una mayor proporción de jóvenes solteros y algunas mujeres, incluso personas con mayor nivel de estudios que los que aparecen en los censos - por ejemplo con preparación para desempeñar oficios, obreros calificados, preparatoria y un profesor -; en este sentido, la migración en Veracruz Central muestra un patrón que incluye a diversos actores sociales, por lo que emerge con un patrón distinto al tradicional, donde dominaba la salida de varones con baja escolaridad, característica también señalada por Ibarraran y Lubotsky (2005:23).

De acuerdo con datos obtenidos de las entrevistas a familiares de los migrantes, la mayor parte de ellos tiene un nivel escolar bajo (55\%), pero aun los que contaban con educación media (31\%) y licenciatura $(3 \%)$, contaban con empleos mal remunerados, y aunque en Estados Unidos obtuvieron empleos de bajo perfil, los consideran de mayor calidad que los que tenían en México, así como con un ingreso superior. Alarcón (2003:7), al analizar el mercado laboral de Los Ángeles para tres grupos étnicos (mexicanos, filipinos y negros nacidos en Estados Unidos), argumentó que los mexicanos contaban con escolaridad más baja que los otros grupos, lo que impacta directamente en el tipo de empleos que logran obtener y establece las condiciones de desventaja social en que viven; sin embargo, estudios más recientes como el realizado por Maloney (2006:1) sobre migrantes indocumentados, arrojaron que solamente $3 \%$ no tenía educación formal, $51 \%$ contaba con educación primaria o menos, $25 \%$ con educación media y $2 \%$ con grado universitario; estas cifras son similares a las obtenidas en el trabajo de campo en Veracruz Central.

Los datos obtenidos por Maloney (2006) y por el trabajo de campo observan que los factores detonantes de la migración no son única- 
mente económicos, y que la migración es considerada como una vía alterna para mejorar la calidad de vida a través de un empleo de calidad, que de cierta forma incluya la posibilidad de llenar expectativas de movilidad social y satisfacción personal, además de lograr mejores condiciones laborales que las que ofrece la región de origen. En este sentido, puede decirse que considerando la información obtenida por la tercera parte de las familias entrevistadas que tienen al menos un varón que emigró a los Estados Unidos, que señalaron que al emigrar contaban con secundaria, preparatoria y licenciatura, así como con empleos y/o terrenos de cultivo, hay un cambio en la ética de trabajo en función de una demanda de empleos de calidad que los que partieron no pudieron encontrar en México, entendiéndose esto como movilidad socioeconómica y logro personal.

\section{Importancia y uso de remesas}

Por su magnitud, las remesas enviadas a México por los migrantes son de gran importancia a nivel macroeconómico; Rosenblum (2002), Lozano $(2004: 4,5)$ y Unger (2005) han señalado que las remesas constituyen una importante entrada de divisas, por lo que son contabilizadas en los informes anuales de la balanza de pagos; estos autores argumentan también que en los discursos oficiales, a las remesas se les ha asignado un papel estratégico no sólo por ser el sostén económico de millones de familias, sino porque también son el motor que mueve y transforma la microeconomía de muchas rancherías, comunidades y regiones del país; esto a pesar de que en términos generales la juventud de la población que migra ha generado un desequilibrio del mercado laboral agropecuario, sobre todo porque la gran mayoría de los migrantes son varones de origen rural.

A escala familiar y con los datos obtenidos en el cuestionario, se encontró que el promedio mensual de los envíos constantes a la zona estudiada es de 4600 pesos, que es mayor al ingreso de aquellos que trabajan en las industrias locales (4 500 pesos) y al de las familias que obtienen ingresos en otros tipos de empleos locales no industriales, o por ingresos provenientes de actividades agropecuarias ( 2 mil pesos); Tuirán señaló una situación similar para el país $(2002: 84,86)$. El pro- 
medio de ingresos por hora recibido por los migrantes veracruzanos, según datos proporcionados por las entrevistas a los parientes, fue de 4.50 dólares por hora (con rangos de 4 a 8 dólares), menor al reportado por Maloney $(2006: 2,19)$ para indocumentados con un promedio de 6.87 dólares, en un rango de 5.50 a 10 dólares por hora y donde el promedio de horas laboradas por semana fue de 62; el mismo autor también señaló que al menos $97 \%$ de los indocumentados entrevistados reportó estar enviando dinero a sus hogares de manera regular.

Las encuestas efectuadas en las localidades de Veracruz mostraron que $61 \%$ de los migrantes envía remesas en forma mensual y regular, $23 \%$ lo hace en forma esporádica, y del $16 \%$ restante, el $12 \%$ no contaba con empleo en el momento de la encuesta, mientras que $6 \%$ había suspendido los envíos. Se encontró asimismo que la regularidad en el envío de remesas está vinculada a la movilidad del migrante, esto debido a que por su situación legal ellos no pueden permanecer mucho tiempo en el mismo lugar o desempeñar la misma actividad; sin embargo, la familia señaló que es una eventualidad común, y sólo tienen que esperar hasta que los envíos se regularicen; al respecto, Maloney (2006:10) indicó que dentro de las preocupaciones de los empresarios de lecherías del estado de Nueva York que emplean indocumentados está precisamente la continua movilidad de éstos, ya que $71.8 \%$ de los trabajadores solamente permanece en los empleos un año o menos; esto también explica la irregularidad de las remesas.

Se encontró que para Veracruz Central, las remesas enviadas al menos en $71 \%$ de los casos estudiados pertenecen a un grupo familiar extenso, al de la familia de origen del varón en el que su propia familia conyugal está inserta; es decir, el dinero enviado no es solamente para su esposa e hijos, sino para su grupo doméstico extenso, lo cual puede ser explicado en parte porque el varón ausente es uno de los proveedores económicos no solamente de su propia familia conyugal, sino de toda la parentela. Entrevistas efectuadas a varones que han retornado señalaron que las remesas pertenecen a un grupo familiar amplio debido a que al emigrar el jefe de familia, deja el cuidado de su esposa e hijos a sus padres y hermanos, provocando esta situación que ahora la esposa no sea independiente y deba someterse a la auto- 
ridad de los suegros y cuñados (varones); de manera similar, Maloney (2006:26) también señaló que la familia tiene una fuerte importancia cultural, por lo que sus necesidades constituyen uno de los motores de la migración de los varones. Lo anterior es reforzado por el hecho de que el dinero que sus encuestados dijeron enviar a México, no solamente representaba el soporte económico para la esposa e hijos, sino también para otros miembros del grupo familiar como hermanos y parientes, y en varias ocasiones hasta para abuelos y tíos. En esta vía vale la pena recordar que en México las condiciones de desempleo, salarios bajos e incertidumbre en los precios de los productos del campo han llevado a las poblaciones rurales a la búsqueda de alternativas o estrategias de sobrevivencia, donde las pautas culturales, como los sistemas de parentesco, han permitido la reproducción económica y social; en este caso, en los grupos familiares extensos la existencia de más de un proveedor económico es necesaria para lograr la reproducción del grupo, y es por eso que las remesas del migrante son consideradas de un grupo doméstico amplio.

Para el caso de Veracruz, el cuadro 2 muestra el destino de las remesas que envían los migrantes a sus familias; se puede ver que aunque la mayor parte de las familias (55\%) orientan un porcentaje alto a la alimentación familiar (49.8\%), otro grupo (31\%) destina al menos $78.6 \%$ en promedio de las remesas recibidas a la compra de activos, donde destaca la construcción de la vivienda con materiales duraderos como concreto, así como la adquisición de semovientes,

Cuadro 2. Distribución porcentual de las remesas mensuales, de acuerdo al porcentaje de familias que las manejan.

Veracruz, México, 2007

\begin{tabular}{lcccccc}
\hline Concepto & Alimentación & Vestido & Escuela & Deuda & Activos* & Ahorro \\
\hline \% Familias & 55 & 39 & 32 & 18 & 31 & 5 \\
$\%$ Ingreso & 49.8 & 27 & 30 & 37.9 & 78.6 & 42.5 \\
\hline
\end{tabular}

* Construcción de vivienda, compra de terrenos, ganado bovino, camionetas, tractores.

Fuente: Trabajo de campo. 
vehículos para trabajo, terrenos para cultivo, potreros, bombas de agua o de energía, etcétera.

Para la zona estudiada, al menos la mitad de las familias que reciben remesas constantes las destinan a mejorar la vivienda y a refaccionar las actividades agropecuarias adquiriendo herramientas y maquinaria que lo faciliten. Por otra parte, también fue perceptible que una parte es orientada al ahorro, destacando también la educación de los hijos, donde al menos 32\% de las familias destinan 30\% de las remesas a la educación privada (cuadro 2), lo cual fue corroborado en las entrevistas a los miembros de las familias. El concepto de deuda se refiere de cierta manera al pago de los mismos activos, o de los préstamos contraídos para pagar el viaje del varón.

Con relación a la preparación académica de las nuevas generaciones y su reciente importancia, éstas están vinculadas a expectativas de movilidad social, según las entrevistas, ya que aproximadamente un tercio de las familias señaló que la educación de los jóvenes permitirá el logro de mejores oportunidades de empleo para no depender del campo o de la migración; de la misma manera, se observó que ha comenzado a vislumbrarse la selección de calidad en la educación, y no únicamente el incremento de los niveles de escolaridad; así, se prefiere la ciudad de Veracruz para cursar los niveles de enseñanza media y las carreras universitarias, no obstante que en las localidades se cuenta con escuelas de enseñanza media.

Al comparar el destino de las remesas a nivel nacional con el de la zona de estudio, se observa que el porcentaje de las remesas destinadas a la cobertura de las necesidades de alimentación es menor en Veracruz, y mayor en el mejoramiento de la vivienda y el ahorro. La figura 1 muestra los porcentajes promedio de uso de las remesas en los hogares, tanto para el país como para el centro de Veracruz.

El ahorro que algunos grupos familiares realizan de una parte de las remesas tiene como objetivo preparar la plataforma económica para el retorno del migrante, así como la creación de nuevos escenarios que difieran de los que le antecedieron a la partida; esto muestra la importancia de un imaginario de mejoría económica y también la búsqueda de cierta calidad de vida y movilidad social, los cuales van fortaleciéndose poco a poco en las localidades de origen; por lo anterior, 
Figura 1.

Comparación de destino de remesas en grandes rubros para el país y para la muestra. Veracruz, México, 2007

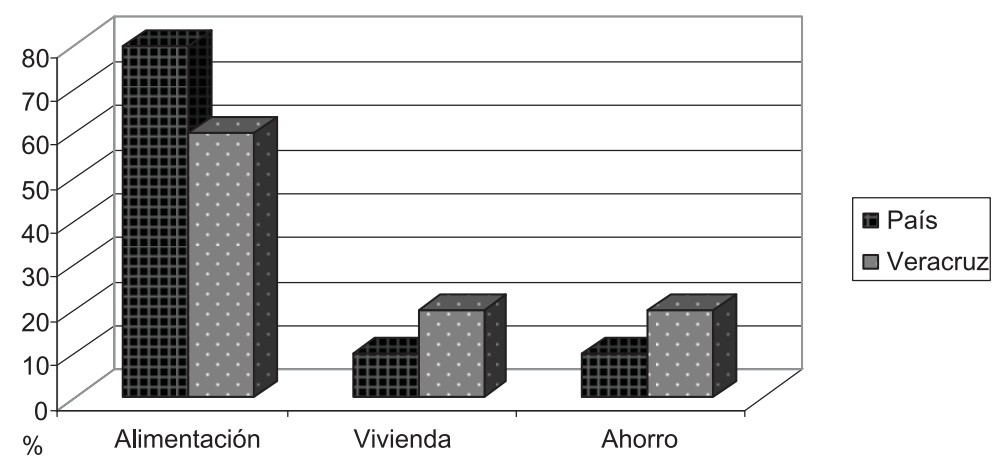

Fuente: Datos tomados de Conapo (2005) y trabajo de campo.

la compra de activos y semovientes va aparejada al ahorro. Cuando a estas familias que ahorran les sumamos la compra de activos que de igual manera constituye una forma de capitalización, se observa que al menos para $36 \%$ de las familias con varones migrantes, el ahorro es primordial y es indicador de que las remesas son suficientes, o que las familias no se encuentran en pobreza extrema. Además, es claro que la compra de bienes mantiene un significado de capitalización para un probable regreso, situación que fue manifestada por las esposas, aun en los casos donde ellas sabían o tenían la certeza de que el marido ya vivía en los Estados Unidos con otra mujer; en estos casos la certeza del retorno no asegura una vuelta al mismo hogar; este mismo significado de la capitalización fue señalado por Roberts (1997:27) como parte de una migración circular.

Al considerar la magnitud cada vez mayor de las remesas y la distribución de las mismas, se puede decir que representan un factor que puede impulsar la actual estática de la producción y la inversión en el sector agropecuario, dando lugar a nuevas dinámicas regionales temporales en las localidades de origen, sin embargo, no se puede negar su importancia en los lugares donde se originan; en este sentido, 
Binford (2002), citando a Arroyo y Berumen (2000:344), calcula que por cada dólar ganado por inmigrantes mexicanos en Estados Unidos, 71.7 centavos permanecen en ese país y 28.3 se remiten a México, mientras que de cada diez dólares, siete se gastan en sustento, viajes y recreación. Esta contabilidad nos muestra una dinámica económica compartida por los países de origen y el de destino, así como una ascendente calidad de vida de los migrantes en los Estados Unidos, comparada con la que llevaban en México, y de cierta forma justifica la importancia del ahorro de remesas, ya que la compra de bienes (vehículos, maquinaria de trabajo) y el mejoramiento de las viviendas muestra la necesidad de recrear en sus localidades la calidad de vida que encontraron en Estados Unidos, y que desean mantener a su probable regreso a casa.

Las entrevistas aplicadas a migrantes que han regresado a las localidades estudiadas indicaron una clara modificación de sus pautas de consumo, ya que al retornar pretenden tener una vida más fácil, refiriéndose a confort doméstico (compra de electrodomésticos), disminución del grado de dificultad al efectuar labores agropecuarias y un colchón económico para empezar alguna actividad (siembra, ganadería, negocio) mientras deciden qué hacer o por si no consiguen pronto una buena oportunidad.

\section{Los grupos domésticos}

A pesar de que la mejoría económica y las aspiraciones de una calidad de vida superior a la que tenían en México son factores de movilización de los migrantes, las pautas culturales de los grupos domésticos perviven con poco menoscabo. Entrevistas y encuestas demostraron que en la mayor parte de las situaciones de la vida cotidiana del grupo doméstico en México, existe una continuidad de los patrones de autoridad como si el varón (jefe de familia) estuviera presente, sobre todo cuando se trata de tomar decisiones económicas o que afectan al grupo familiar, de tal manera que en términos de autoridad la ausencia del jefe de familia es solamente física, y esposa e hijos ante esta ausencia dependen moral y económicamente de la familia del varón, generando una continuidad de los patrones jerárquicos tradicionales. 
El 79\% de los varones migrantes han partido solos y su cónyuge e hijos quedado bajo la autoridad económica y moral del padre (solamente $21 \%$ de los migrantes eran solteros); los datos muestran que en la mayor parte de los hogares se reproducen los roles patriarcales que restringen la independencia femenina. Las mujeres (esposas o concubinas) de los varones migrantes no siempre gozan de independencia económica, por lo que no deciden sobre la distribución de las remesas. En el total de las familias estudiadas se observó que solamente en $31 \%$ de los hogares las mujeres administran las remesas, mientras en $42 \%$ es la parentela del varón (padres y hermanos del marido, principalmente) la que distribuye y administra, y en $19 \%$ es directamente el varón quien a la distancia señala la distribución del dinero que envía (figura 2).

Los datos de la figura 2 muestran que en la mayor parte de los hogares entrevistados las esposas de los varones migrantes están supeditadas a controles patrilineales del grupo doméstico extenso del marido, donde los varones continúan ejerciendo la autoridad en su sentido más amplio; mientras que en el caso de las mujeres que viven en unión libre el control del grupo familiar del varón es aún

Figura 2.

Figuras domésticas que toman las decisiones, respecto de la distribución de las remesas, en porcentaje.

Veracruz, México, 2007

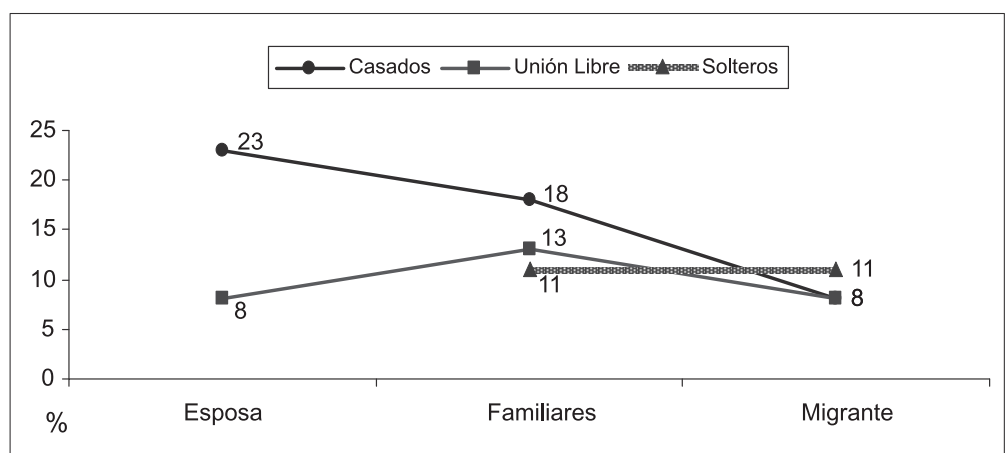

Fuente: Trabajo de campo. 
mayor. La voluntad y autoridad del varón es ejercida a través de los padres o hermanos, o de la madre si ésta es viuda, y es mediante órdenes expresas que el migrante envía por teléfono o carta. En el caso de los varones solteros, padres o hermanos administran las remesas, si bien aseguran que la distribución que realizan es la voluntad del migrante.

Aunque las razones que dieron aquellas personas que cobran las remesas para decidir sobre la distribución del dinero fueron variadas, las respuestas destacan el sentido tradicional de la supremacía del varón, vinculado a su papel de proveedor económico dentro del grupo doméstico. La prevalencia del papel masculino a distancia, a través de la línea del varón, incorpora argumentos como "a mí me mandan el dinero", "yo sé qué hacer con ellos", "el esposo que lo gana decide quién lo administra y en qué se gasta".

Por lo anterior, en los casos estudiados, no se puede hablar de un rompimiento abrupto de las jerarquías, pues de cierta manera el mundo de los varones continúa con la supremacía en todas las esferas de la vida del grupo familiar. A pesar de que las mujeres adquieren jefatura doméstica, de esta forma solamente incrementan sus niveles de dependencia frente a los ingresos provenientes del cónyuge migrante, puesto que por una serie de factores culturales y sociales no tienen la libertad de decisión ni sobre las remesas ni sobre su persona, ya que están supeditadas a una autoridad más amplia, pues viven bajo el escrutinio de los parientes políticos, además del de su propia comunidad.

De cierta manera, los sistemas de parentesco patrilineales y las jerarquías explican la poca cantidad de mujeres migrantes, aunque a decir de Cuartas (2002:14), los sistemas normativos patriarcales al interior de la familia y las poderosas diferencias de género disminuyen las posibilidades de migración de las mujeres, pues los tradicionales papeles productivos y reproductivos restringen sus tomas de decisiones.

Así, la esfera femenina mantiene la acumulación histórica de obligaciones y cargas domésticas, como el cuidado de los hijos y la obediencia. Esto es determinante entre las esposas de los migrantes, ya que el grupo familiar les reconoce y otorga la jefatura, pero sólo para 
incrementar sus obligaciones y tareas cotidianas, donde las responsabilidades son mayores pues si las cosas salen mal, o si surgen problemas con los hijos, ellas reciben el peso de las recriminaciones de la parentela del marido y de la suya propia. Aunque no todas las mujeres aceptan este papel, la propia comunidad genera las condiciones para la sumisión, ya que las convierte en el blanco de las miradas que critican y vigilan su comportamiento. Sin embargo, es necesario señalar el desempeño femenino en un papel crecientemente importante, como lo es el ser gestoras de la continuidad de los sistemas tradicionales de organización patrilineales, así como por procurar la preservación de la unidad familiar, aprobando y manteniendo la jerarquía masculina en un matrimonio a distancia, la unidad familiar y su nuevo papel en la comunidad.

Por otra parte, esto representa una reconstrucción de las vidas de los varones ausentes, creando una nueva identidad y sin perder el vínculo familiar. Por tanto, puede decirse que en Veracruz Central existe una continuidad de las jerarquías culturales tradicionales, donde se siguen ejerciendo y reproduciendo los roles masculino a nombre del bienestar del grupo familiar, pero también construyendo la plataforma de retorno del varón ausente.

Herrera (2001) y D'Aubeterre (2000 y 2001:14) han reportado información similar, indicando que con la migración se conforma un tipo de conyugalidad a distancia que supone la no co-residencia, las continuas negociaciones entre marido y mujer en la toma de decisiones concernientes a los procesos de producción y reproducción que involucran al grupo doméstico, la fidelidad femenina y el mantenimiento de los bienes sociales y simbólicos tales como el honor, el prestigio y el respeto al marido y al hogar. Asimismo, Herrera (2002) señala, citando a Hondagneu (1997), que esta nueva modalidad de familia implica diversas formas de explotación económica encubiertas por la ideología del parentesco y no conlleva a un cuestionamiento de las representaciones hegemónicas de género.

De esta manera, podemos aseverar que la dinámica social que se va creando genera un modelo de familia que no necesariamente es distinto al tradicional, ni rompe con los patrones hegemónicos patrilineales de la familia mesoamericana, descrita por Robichaux (1997 
y 2002) y Pauli (2002), y cuya prevalencia en Veracruz Central fue analizada por Del Ángel y Mendoza (2002). A pesar de que se trastocan muchas de las prácticas cotidianas, perviven los grupos familiares extensos con sistemas de herencia patrilineales de la tierra, residencia y jerarquías masculinas. Dentro de la reproducción de los roles masculinos, también fue notable el ejercicio de la libertad tradicional de los varones, en oposición a la restringida libertad de las mujeres para la formación de nuevos hogares, ya que los varones toman concubinas o esposas en los Estados Unidos, con pleno conocimiento de su grupo familiar. Al momento de realizar esta investigación, el estado civil de los migrantes (figura 3) mostró que del total de los varones que al partir estaban casados en Veracruz, 21\% formó un nuevo hogar en los Estados Unidos, mientras que en los casos de aquellos que eran solteros al momento de abandonar el país, 50\% formó una familia; en todos los casos la unión se llevó a cabo con mujeres migrantes indocumentadas mexicanas, en su mayor parte veracruzanas. La formación de una nueva familia en los Estados Unidos se llevó a cabo en un promedio de cuatro años después de haber salido de México; los comentarios de los varones que han retornado mostraron que la for-

Figura 3.

Estado civil de migrantes veracruzanos. Veracruz, México, 2007

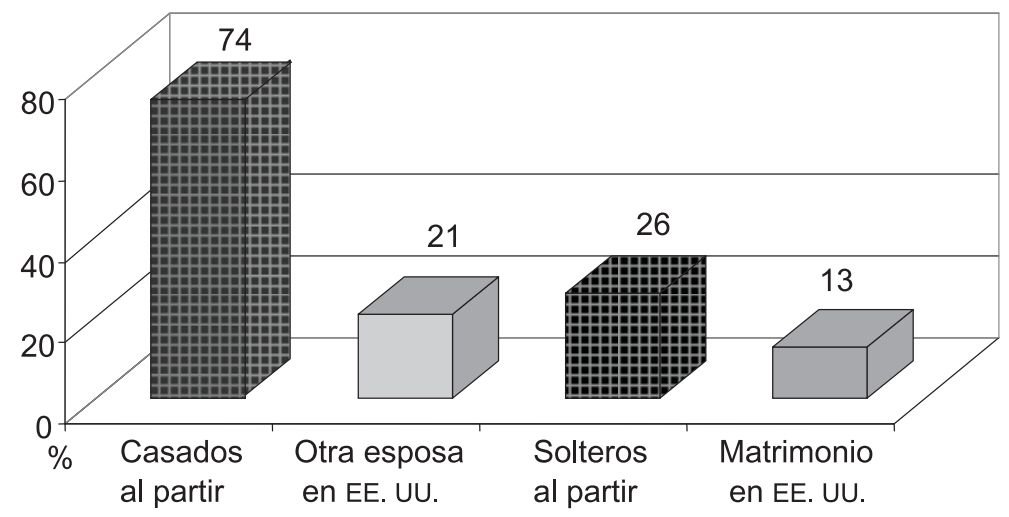

Fuente: Trabajo de campo. 
mación de un nuevo hogar en los Estados Unidos se debió también a la reproducción de las formas de vida de sus lugares de origen y a la adaptación al lugar.

Las entrevistas mostraron que las esposas de los varones que habían formado un nuevo hogar en los Estados Unidos, aunque conocían la situación del varón ausente, consideran que es importante mantener los lazos y el soporte económico para la familia de México. Así, la infidelidad aparece como un rasgo común y aceptado, y no evita que la mayoría de los varones pierda contacto con el grupo doméstico extenso de origen, pues esto crea la oportunidad de regresar en caso de fracaso económico, por cansancio y vejez, por enfermedades graves o bien por deportación.

Podemos decir que el sistema de parentesco crea las condiciones para el regreso de los migrantes al interior de un grupo familiar y al país, por eso la parentela vela por el cumplimiento de sus deseos, la distribución de las remesas y por su futuro, que es un futuro compartido desde el punto de vista de modificación de la calidad de vida e incremento de la riqueza del grupo familiar extenso. Además, las entrevistas indicaron que en la mayor parte de los migrantes está el deseo de retornar a México; situación similar reportó Maloney (2006:2), pues al menos $68 \%$ de los migrantes confesó que entre sus planes está el de retornar a su país en un plazo más o menos cercano, mientras que $31 \%$ planeaba estar en los Estados Unidos largo tiempo.

La importancia de la pertenencia a un grupo doméstico extenso trasciende la frontera, ya que los datos obtenidos revelaron que la mayor parte de los migrantes (68\%) habita con diversos tipos de personas en los Estados Unidos, en su mayoría parientes unidos tanto por parentesco biológico como por, en menor proporción, políticos; mientras que el restante $32 \%$ vive con amigos $u$ otros migrantes también mexicanos, y muy pocos viven solos (figura 4).

Dentro de los grupos familiares formados en Estados Unidos, destacan grupos de familia extensa en $48 \%$ de los hogares que habitan los varones, y aunque los roles económicos pueden estar distribuidos entre varones y mujeres, es perceptible la jefatura de los varones en la toma de decisiones y en la protección de la integridad física de las mujeres; mientras, la esfera doméstica como cocinar y criar a los niños, le atañe 
Figura 4.

Continuidad y reproducción de las formas de vida familiares.

Veracruz, México, 2007

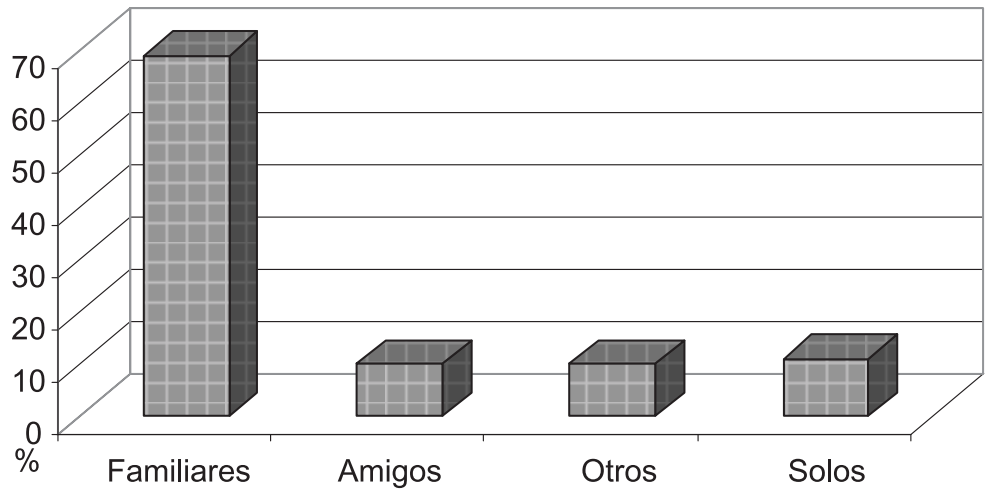

Fuente: Trabajo de campo.

a las mujeres. Cuando los hombres toman esposa, ésta, normalmente, se integra al ámbito doméstico y el hombre se constituye en proveedor económico. De manera similar a las localidades de origen, la convivencia de los grupos domésticos extensos muestra la recreación de patrones culturales, formas de vida, costumbres (sistemas de alimentación y parentesco ritual), idioma, reuniones familiares y de paisanos.

Las perspectivas de retorno al hogar, las uniones con mujeres preferentemente mexicanas, el mantenimiento de usos y costumbres, la reproducción de formas de vida y de jerarquías masculinas en el seno de los grupos familiares en ambos lados de las fronteras, muestran la perpetuación de los rasgos culturales y una barrera cultural para la asimilación de la cultura estadounidense. En el mismo sentido, algunos de los programas sociales gubernamentales enfatizan la reproducción de las jerarquías masculinas; por ejemplo, Lozano (2004) y Hatton y Williamson (2003) argumentan que la acción del Estado está orientada a mantener la lealtad de los migrantes con sus comunidades de origen a través de la promoción del vínculo entre 
los migrantes y sus familias, enfatizando la importancia de la solidez familiar en la existencia de una familia de padres e hijos y donde la figura del varón es primordial; por otra parte, estas acciones también favorecen la conformación de oleadas de sistemas migratorios temporales o transnacionales en lugar de sistemas migratorios permanentes, en los que existe una mayor probabilidad de que los migrantes no establezcan fuertes vínculos económicos y sociales en los Estados Unidos. El mismo autor también señala que la experiencia mexicana, y particularmente la de la administración de Vicente Fox, es un excelente ejemplo de la política de cortejo y vinculación con los migrantes.

El débil vínculo con la cultura estadounidense, de acuerdo con Winders (2005:688-689), se debe a que los indocumentados son aceptados como trabajadores, pero no como miembros de la comunidad. En entrevistas aplicadas a varones que han regresado a las localidades, al preguntárseles por los motivos para el retorno, mostraron la fuerte interiorización de un significado de hogar ambivalente, que de alguna manera implica manifestaciones espaciales, temporales y sociales, que determinan la reproducción de formas de vida de las localidades en los lugares de destino y viceversa, así como la esperanza del regreso; es decir, se mezclan patrones de resistencia y cambio, donde hogar significa familia y recuerdos de las vivencias en sus localidades y con su grupo familiar, pero también el mejoramiento material que ofrece el lugar de destino, siendo esta ambivalencia una vía para sobrellevar situaciones nuevas.

Para los migrantes veracruzanos, Estados Unidos es un hogar temporal de mejoría económica, pero nunca será su hogar; la añoranza de los lugares que dejaron, del pasado, de su comunidad y de sus familias, incluyendo estilos de alimentación, convivencia y diversión, explica su baja integración con la población americana; el uso del español y su poco interés en aprender inglés, también impide la interiorización de la idea de que el lugar al que emigraron es el hogar, ya que el hogar es lo que dejaron.

La idea de ir creando poco a poco y a través de los parientes en México las condiciones favorables para el regreso, reproduciendo una calidad de vida distinta a la que tenían antes de partir, también mani- 
fiesta la asimilación de otras formas de vida; Falicov (2001:38) le llamó "resiliencia a la pérdida ambigua", y la relaciona con la habilidad de adaptación al cambio pero también de mantener suficiente continuidad con la cultura original. Se puede decir que el parentesco y otros tipos de redes, que han permitido a los migrantes veracruzanos ingresar a los Estados Unidos, al mismo tiempo constituyen una fortaleza para la conservación del capital cultural y designan una baja receptividad hacia la asimilación total.

\section{El papel de las redes sociales}

Al tomar a la familia como unidad migratoria, se observó que diversos tipos de redes, tanto sociales como económicas, y los vínculos de parentesco, son estrategias que desempeñan un papel importante en la migración, que la impactan y la refuerzan, y como señaló Herrera (2002:91), explican la decisión de migrar; asimismo, comienzan a operar desde el lugar de origen, hasta la inserción en los lugares de destino.

La información obtenida en Veracruz Central mostró que la decisión para migrar no es totalmente individual, sino en parte también es familiar; esta característica se fundamenta en la importancia de las redes de parentesco, ya que el migrante va a emprender una tarea que va a beneficiar al grupo familiar, por ello, el grupo también participa en el financiamiento de todo el viaje o de una parte. Las entrevistas mostraron que la familia de origen, y en menor medida los parientes políticos, son los primeros amortiguadores de los costos de traslado al lugar de destino de los varones que emigran, y en muchas ocasiones a partir de un endeudamiento por el que responden los parientes y que se pagará con las remesas. Los gastos incluyen pasajes, (camión, autobús y en algunos casos avión) hasta algún lugar de la frontera, el cruce de ésta, que se realiza contratando los servicios de algún pasador también llamado "coyote"; dentro de los costos se incluye también en algunos casos un pago para los agentes fronterizos. Este tipo de entrada es denominada "legal" de manera regional, ya que los sistemas de cruce de la frontera son llevados a cabo a través de algún puente fronterizo, lo que equivale a pagar ciertas sumas de dinero en 
pesos a oficiales mexicanos, y en dólares a los norteamericanos; en estos casos la entrada es con pasaporte pero sin visa.

El cuadro 3 muestra que $84 \%$ de los migrantes recibió apoyo de la parentela biológica y política para partir. Se puede considerar que las mismas redes tienen un papel preponderante en el ingreso y en la instalación o adaptación del migrante en los Estados Unidos; por ejemplo, se encontró que $81 \%$ de los veracruzanos que emigraron tenía cuando menos un pariente (biológico o político) en Estados Unidos. Estas mismas redes de parentesco crearon la plataforma para recibir al $60 \%$ de los migrantes, y para colocar en empleos al $32 \%$. El cuadro 3 permite observar que el parentesco biológico es la red más importante, si bien el parentesco político también figura, y su importancia es similar a la de las redes de amistad; al respecto, Herrera (2002:3), Chiquiar y Hanson (2002) y Guzmán et al. (2004:29) señalan que los distintos lazos que se entretejen entre familiares tanto en la comunidad de origen como en los Estados Unidos estimulan la migración y los linderos de bienestar económico.

El mismo cuadro también señala que en la obtención de un empleo las redes de amistad son más importantes. Las entrevistas con los migrantes que retornaron y con los parientes de los migrantes indica-

Cuadro 3. Redes sociales de ayuda para emigrar y establecerse en EU. UU. en porcentaje de acuerdo al muestreo.

Veracruz, México, 2007

\begin{tabular}{lcccc}
\hline Conceptos & $\begin{array}{c}\text { Parientes } \\
\text { biológicos }\end{array}$ & $\begin{array}{c}\text { Parientes } \\
\text { políticos }\end{array}$ & Amigos & Nadie \\
\hline $\begin{array}{l}\text { Conocidos en EU. UU. } \\
\text { Lo recibieron en EU. UU. }\end{array}$ & 70 & 11 & 10 & 8 \\
$\begin{array}{l}\text { Apoyo econ. } \\
\begin{array}{l}\text { En su lugar de } \\
\text { origen al partir }\end{array}\end{array}$ & 76 & 13 & 29 & 10 \\
$\begin{array}{l}\text { Le ayudaron a } \\
\text { conseguir } \\
\text { trabajo en EE. UU. }\end{array}$ & 26 & 8 & 11 & 5 \\
\hline
\end{tabular}

Fuente: Trabajo de campo. 
ron que las redes de amistad se forman con personas que pertenecen a la misma zona de origen, aunque no siempre son de la misma localidad y algunas veces sólo se conocen en el camino. Sin duda, las redes sociales ampliadas representan una variable de suma utilidad para la integración y obtención de empleos; en este sentido, Alarcón (2003:1) considera que mediante las redes sociales no solamente se construyen nexos personales, sociales y económicos con la sociedad receptora, sino también se llega a la formación de concentraciones de migrantes originarios de una misma región en ciertas áreas de Estados Unidos.

Es en estas circunstancias que surge otro tipo de redes, de carácter económico, donde otros personajes, normalmente compatriotas, aparecen y funcionan como "enganchadores" de mano de obra no calificada, los cuales pueden aparecer desde las localidades de origen mediante cierta cantidad en efectivo. Este tipo de redes binacionales ofrecen protección a los indocumentados y ayudan a su incorporación al mercado laboral informal. Vinculan a los individuos y a las comunidades de origen con las de destino y son determinantes para reducir los costos y riesgos asociados con el movimiento migratorio, así como para contribuir a sostenerlo, recrearlo y perpetuarlo. Krissman (2001:17-18) y Fitzgerald (2000) mencionan en estudios sobre migrantes mexicanos que las redes sociales son cada vez más complejas, ya que envuelven más actores, haciéndose necesario profundizar en el análisis de su complejidad. Krissman sugiere que la figura de los intermediarios (brokers) aparece como red de conexión, para proveer de mano de obra a los empleadores, independientemente de que empleadores o la familia del migrante carguen con los costos del intermediarismo.

Estas vías permiten el acceso a redes económicas que favorecen el reclutamiento de personal por parte de los empleadores en los Estados Unidos y están constituidas por una cadena de personajes. Consisten en un tipo de intermediarismo que se construye desde los países y localidades de origen, fronteras y el país de destino, tales como transportadores, agentes, choferes, etcétera, esto también favorece a empleadores para tener acceso a trabajadores baratos, seguros, fieles y de alta productividad. Un informe del Human Rights Center (2004), de la Universidad de California, señala el caso de algunos trabajadores chinos, mexicanos y vietnamitas que obligados por su situación 
ilegal, realizan ciertas formas de trabajo forzado en varios lugares de Estados Unidos.

Otra manera de afianzar la permanencia de trabajadores ya reclutados, es mediante mecanismos de facilitación que proveen los empleadores, creando el marco para la construcción de ciertos vínculos entre trabajadores y empleadores. Datos obtenidos en entrevistas directas con empresarios de Nueva York en 2005 y 2006, señalaron la importancia de la creación de vínculos simbióticos donde la interdependencia asegure el logro de objetivos de cada una de las partes. En este sentido, los empleadores reconocen la derrama económica que generan los trabajadores indocumentados por su fuerte ética de trabajo, en una industria que genera 700 millones de dólares en 750 mil acres, sólo para el estado de Nueva York. Las entrevistas pudieron realizarse gracias al programa Building Cross-Cultural Understanding among NYS Dairy Farmers del Departamento de Administración y Economía Aplicada de la Universidad de Cornell. Este programa, dirigido por Thomas R. Maloney, capacita a empresarios que emplean indocumentados con el fin de lograr un cambio de actitud en ellos y así mejorar las relaciones entre empleadores y trabajadores. Los empresarios viajan a México y son puestos en contacto con las familias de sus trabajadores, para posteriormente regresar a Nueva York e impartir pláticas sobre sus impresiones a otro grupo de patrones de indocumentados; la meta es revalorizar la convivencia de dos culturas, mejorar las relaciones interpersonales y asegurar la permanencia de los indocumentados, donde está comprometido el futuro de la industria lechera (Maloney, 2007).

Aunque el motor del programa es mayormente económico, manifiesta la necesidad de afianzar a los trabajadores de alta eficiencia laboral; lo anterior se debe a la alta movilidad de los indocumentados, y al hecho de que éstos orientan cada vez más sus expectativas a obtener empleos urbanos en el área de servicios. En las entrevistas los empresarios reconocieron que no es posible conseguir en su país empleados dispuestos a realizar las actividades de lechería, por lo que fundamentan el programa en la reducción del abismo cultural entre ambas partes y en proveer de condiciones de confort a los trabajadores para promover su estabilidad. 
De esta manera, las preocupaciones de los empresarios coinciden con las proyecciones de la Oficina de Estadísticas Laborales de Estados Unidos respecto a un excedente de empleos para 2008 sin trabajadores para ocuparlos, ya que cerca de $57 \%$ de los empleos creados requerirán personal con un modesto entrenamiento y una educación formal por debajo del nivel de preparatoria (Conapo, 2005). Por su parte, Ibarraran y Lubotsky (2005:23), y Card y Lewis (2005:19), en estudios de indocumentados en Estados Unidos, señalaron que tales trabajadores están dispuestos a efectuar actividades que pocos americanos están dispuestos a realizar.

Los empresarios, vinculados a actividades de la industria lechera y con hatos de entre 800 y 5 mil animales, señalaron que el uso de trabajadores hispanos se ha incrementado a partir del año 2000, destacándose los mexicanos, y de éstos los veracruzanos; sin embargo, la duración de la prestación del servicio es muy corta, la mayor parte menor a un año. La importancia de retener y estabilizar a los trabajadores lleva a los empresarios a sentirse obligados a protegerlos. Así, los proveen de casas-habitación confortables con servicios de calefacción, televisión por cable, suministro de alimentos del supermercado, ya que no dominan el idioma y pueden ser deportados, etcétera. Aunque los patrones son proveedores de una nueva calidad de vida para los trabajadores, también refuerzan las formas y pautas culturales, ya que consideran que es importante recrear los hábitos, como el de la alimentación, por lo que importan frijoles, chiles, etcétera e incluso algunos siembran maíz para la elaboración de tortillas, además de la promoción de las fiestas comunes, como cumpleaños, Navidad, Día de Muertos. Otras facilidades que en este caso se otorgan a los trabajadores son vales de despensa o de atención médica y compensación por trabajo en días de fiesta. Uno de los empresarios llamó la atención sobre el lavado de ropa, históricamente alejado del ámbito masculino en la sociedad mexicana, de tal manera que aparece dentro de las prestaciones.

El paternalismo en un país extraño es valioso en temporadas de añoranza de la tierra de origen y asegura la permanencia y fidelidad de los trabajadores, que agradecidos se comprometen a trabajar más y mejor, aunque las remuneraciones que reciben por su trabajo a me- 
nudo son menores a las pagadas a trabajadores legales o americanos. Normalmente este tipo de migrantes con baja escolaridad realizaba en México trabajos pesados con bajas remuneraciones, por lo que la nueva situación y la protección de los empleadores los estimula a mejorar su desempeño, y aunque esto facilita la adaptación, la situación de dependencia dificulta la integración.

Las redes sociales señaladas perpetúan la migración internacional; es decir, la existencia de redes sociales (parientes y amigos) y económicas (intermediarios o brokers, reclutadores y patrones) constituye un vínculo importante para la afluencia de migrantes a los Estados Unidos.

\section{Conclusiones}

Veracruz es una de las entidades federativas donde el fenómeno migratorio internacional emerge de manera abrupta; uno de los factores detonantes de este fenómeno es la incapacidad estructural para presentar opciones que permitan cubrir las nuevas expectativas de una población cuya ética de trabajo y aspiraciones se han modificado, los cuales demandan por empleos de calidad, mayor remuneración y otros estándares de vida.

De acuerdo con los resultados de las entrevistas realizadas en las comunidades de Veracruz Central, gran parte de los migrantes indocumentados tiene como expectativas mejorar su calidad de vida y obtener empleos de mejor calidad y mejor remunerados, que no encuentran en las localidades de origen. El estudio encontró que en la mayor parte del grupo de varones que emigraron, el desempleo o la pobreza extrema no fueron los motores primarios para hacerlo, sino la búsqueda de alternativas para sus expectativas de vida, que no pueden lograr con las condiciones actuales de empleos, refiriéndose esto a satisfacción laboral y movilidad económica. Los empleos que los migrantes desempeñan en los Estados Unidos son considerados de mayor calidad y orientados principalmente al área de servicios, donde reciben un mayor salario por hora de trabajo que en un día completo de trabajo en México. Por otra parte, los individuos que migran toman un papel de promotores del desarrollo en su localidad, ya que 
gran parte de las remesas se destina al incremento de bienes de capital como tierras, maquinaria y ahorro, así como a elevar las oportunidades de movilidad social de sus hijos mediante la preparación académica.

La investigación mostró también que los cambios en el interior de la estructura del grupo familiar, donde las mujeres en ausencia del esposo toman un papel de jefas de familia, solamente impactan el plano doméstico, ya que más que la ruptura de las unidades domésticas, se observó la continuidad de los sistemas de parentesco, marcada por la interacción con el grupo doméstico extenso del varón, donde los lazos familiares son tan importantes que se siguen recreando. El uso y control de las remesas por parte de las mujeres está supeditado a una serie de controles familiares en donde se sigue ejerciendo y reproduciendo el papel masculino a nombre de la familia. Por último, las mujeres que se quedan a cargo del cuidado de la familia no disminuyen, sino más bien incrementan sus niveles de dependencia frente a los ingresos provenientes del esposo migrante, puesto que por una serie de factores culturales y sociales no tienen la libertad de decisión sobre estos recursos.

A raíz del fenómeno migratorio masivo en Veracruz Central, no se puede hablar de nuevos modelos de familia, aunque aparentemente surge una familia monoparental desintegrada; asimismo, los datos arrojaron una separación física del proveedor económico y una perpetuación del modelo tradicional de grupos familiares extensos con jerarquía masculina y liderazgo a cargo de los varones; se destaca también la aparición de un matrimonio a distancia, donde las decisiones siguen a cargo de los esposos ausentes a través de los parientes del mismo varón. Por lo anterior, el análisis del funcionamiento de los hogares donde el padre es migrante, no mostró el rompimiento de jerarquías y reveló la permanencia de representaciones de género hegemónicas, de reglas de parentesco y reforzamiento de roles familiares tradicionales.

Diversas redes sociales fortalecen el fenómeno migratorio: las redes sociales y económicas intervienen y facilitan la salida y el retorno, así como la adaptación en los lugares de destino y la búsqueda de empleos; sin embargo, dificultan la integración a la cultura america- 
na, aunque promueven el retorno y crean la plataforma para el regreso del migrante, modificando el entorno de confort doméstico y de trabajo; también es un hecho que refuerzan la continuidad de los roles clásicos familiares entre la familia que se queda y la que se integra en al país receptor. Finalmente, cabe agregar que el estudio de caso de migrantes indocumentados demuestra que la actual migración operada con ayuda de las redes familiares explica y refuerza la continuidad de los patrones culturales (idioma, parentesco, residencia) y crea la figura migratoria de varones con capital social incrementado, en la que el significado de hogar emerge en forma compleja y contradictoria, ya que incluye un sentido de pertenencia temporal en los Estados Unidos y permanente en México. Esto crea una ambivalencia sobre el significado de hogar, ya que al emigrarse reproducen y extrañan antiguas formas de vida y costumbres, y al regresar a México reproducen parte de las que conocieron en los Estados Unidos.

\section{Bibliografía}

Alarcón, Rafael (2003), “Inmigrantes mexicanos en Los Ángeles: integración económica y social en una ciudad región-global", Primer Coloquio Internacional Migración y Desarrollo: Transnacionalismo y Nuevas Perspectivas de Integración, Zacatecas, México, 23-25 de octubre, www.migracion y desarrollo.org.

Banco Nacional de México (2004), Las remesas familiares en México, Informe, noviembre, http://portal.sre.gob.mx/ime/pdf/ Remesas_Familiares.pdf. Consultado el 12 de febrero de 2006.

Binford, Leigh (2002), "Remesas y subdesarrollo en México", Relaciones, núm. 90, vol. XXIII, pp. 117-158, Puebla, México, primavera.

Card, David y Ethan G. Lewis (2005), "The Diffusion of Mexican Inmigrants during the 1990s: Explanations and Impacts", NBER Working Paper Series 11552, National Bureau of Economic Research, Cambridge, MA, 02138, agosto, http://www.nber. org/papers/w11552. 
Carral C., Magdalena (2005), Integración, migración y cooperación: el caso de México, Instituto Nacional de Migración, México, http:// www.iadb.org/mif/V2/spanish/files/cuevas_spaJP05.pdf

Comisión Económica para América Latina y el Caribe (CEPAL) (2001), Panorama Social de América Latina 2000-2001, Santiago de Chile, CEPAL.

Consejo Nacional de Población (2005), “Los hogares de los mexicanos en Estados Unidos”, Boletín Conapo, año VIII, núm. 20, http:// www.conapo.gob.mx/publicaciones/intensidadmig/cap03.pdf Cuartas Aravena, Verónica (2002), Mexican Women and Migration: The Effects of Education and Family Status, Thesis Submitted to the Graduate Faculty of the Louisiana State University and Agricultural and Mechanical College in partial fulfillment of the requirements for the degree of Master of Arts in The Department of Sociology.

Chiquiar, Daniel y Gordon H. Hanson (2002), "International Migration, Self-Selection, and the Distribution of Wages: Evidence from Mexico and the United States", Documento de trabajo 9242, National Bureau of Economic Research, Cambridge, MA, octubre de 2002, http:/ / www.nber.org/papers/w9242

D’ Aubeterre, María Eugenia (2000), “Arbitraje y adjudicación de conflictos conyugales en una comunidad de transmigrantes originarios del estado de Puebla", en L. Binford y M.M.E. D'Aubeterre, Conflictos migratorios transnacionales y respuestas comunitarias, Instituto de Ciencias Sociales y HumanidadesBUAP, Puebla.

(2001), ¿Todos estamos bien? Género y parentesco en familias de transmigrantes poblanos, LASA, Washington, D.C., septiembre.

Del Ángel P., Ana Lid y Martín Mendoza (2002), “Familia totonaca, expresión cultural y sobrevivencia", Papeles de Población, Nueva época, año 8, núm. 32, México.

De Oliveira Orlandina, M. Eternod y Ma. de la Paz López (1999), “Familia y género en el análisis sociodemográfico", en Brígida García (coord.), Mujer, género y población en México, El Colegio de México, México.

Díaz, M. Eileen y Felicia B. Leclere (2002), “Selection, Context, or Both? The English Fluency of Mexican Immigrants in the American 
Midwest and Southwest", Population Research and Policy Review, núm. 21, Kluwer Academic Publishers, Los Países Bajos.

Domínguez del Olmo, J. (1999), “Compromisos de El Cairo y Beijing en materia de familias y mujer", Conferencia magistral en III Foro Regional: Familia y Mujer, Ciudad Victoria, Tamaulipas, México, 6 de agosto, http://www.cddhcu.gob.mx/camdip/ comlvii/compyd/f03-02.htm

Falicov Jaes, Celia (2001), "Migración, pérdida ambigua y rituales", Perspectivas Sistémicas. La Nueva Comunicación, núm. 69, noviembre, febrero, http:/ / www.redsistemica.com.ar/migracion2.htm (13 de 13)07/02/2006 21:32:56

Fitzgerald, David (2000), "Negotiating Extra-Territorial Citizenship: Mexican Migration and the Transnational Politics of Community", en Rainer Bauböck, Agnes Heller y Aristide R. Zolberg (eds.), Societies of Immigration, Aldershot, Inglaterra, Avebury.

García Z. Rodolfo (2004), “Migración internacional, tratados de libre comercio y desarrollo económico en México y Centroamérica", III Conferencia Internacional de la Red de Estudios sobre el Desarrollo Celso Furtado, Río de Janeiro, Brasil, 4 de mayo.

Guzmán, M.G., Joseph H. Haslag y Pia M. Orrenius (2004), "Accounting for Fluctuations", en Social Network Usage and Migration Dynamics, Research Department Working Paper 0402, Dallas, TX, 4 de agosto.

Hatton Timothy, J. y Jeffrey G. Williamson (2003), "What Fundamentals Drive World Migration?", Discussion Paper No. 2003/23, United Nations University, World Institute for Economics Development Research, marzo.

Herrera Gioconda (2002), “Migración y familia: una mirada desde el género", Programa de Género de FLACSO, 1er Encuentro de LASA sobre Estudios Ecuatorianos, FLACSO Ecuador, 18-20 de julio.

Human Rights Center, Universidad of California, Berkeley (2004), “Hidden Slaves. Forced Labor in the United States", septiembre, httptp: //www.hrcberkeley.org/research/hiddenslaves.html.U.S.A.

Hurtado, Margarita (2003), “Dinámica de los estados centroamericanos y su relación con la agenda de migración", Programa de Migración, FLACSO, Guatemala, noviembre. 
Ibarraran, Pablo y Darren Lubotsky (2005), "Mexican Immigration and Self-Selection: New Evidence from the 2000 Mexican", Census. Working Paper 11456. National Bureau of Economic Research, Cambridge, MA, http://www.nber.org/papers/w11456.

Jiménez, T. y Nuria Costa (2006), “El fenómeno migratorio supone la desintegración del $36 \%$ de las familias centroamericanas", en Mujer Actual, http:/ / www.mujeractual.com/sociedad/temas/ migracion.html

Krissman, Fred (2001), 'Them' or 'Us'? Assessing Responsibility for Undocumented Migration from Mexico", Working Paper 46, Center for Comparative Immigration Studies.

Leiken, Robert S. (2000), The Melting Border Mexico and Mexican Communities in the United States, Center for Equal Opportunity, Washington, D.C.

Lewis Jessa, M. (2005), "Strategies for Survival: Migration and Fair Trade-Organic Coffee Production in Oaxaca, México", Working Paper 118, The Center for Comparative Immigration Studies, University of California, San Diego.

Lozano Ascencio, Fernando (2004), "Tendencias recientes de las remesas de los migrantes mexicanos en Estados Unidos", Working Paper 99, Center for Comparative Immigration Studies, University of California, San Diego, abril.

Maloney, Thomas (2006), Dairy Farm Manager's Study Trip to Mexico, Human Resource Management, Library Vivo Life Sciences. Cornell University, Ithaca N.Y., http://vivo.cornell.edu/ entry?home=1\&uri=http $\% 3 \mathrm{a} \% 2 \mathrm{f} \% 2 \mathrm{fvivo}$.library.cornell.edu $\% 2 \mathrm{fns}$ $\% 2 f 0.1 \% 23$ individual31084.

Maloney, T. R. y David C. Grusenmeyer (2005), Survey of Hispanic Dairy Workers in New York State. Department of Applied Economics and Management, College of Agriculture and Life Sciences, Cornell University, Ithaca, New York. Report RB 2005-02. (2007), "Building Cross-Cultural Understanding among NYS Dairy Farmers", Department of Applied Economics and Management. College of Agriculture and Life Sciences, Cornell University, Ithaca, New York. Entrevista directa sobre migración de veracruzanos a los Estados Unidos, enero 3 y 4, Veracruz, Ver. 
Martin, Philip (2003), "Economic Integration and Migration.The Mexico-US Case", Discussion Paper, núm. 2003, United Nations University, World Institute for Development Economics Research.

Pauli, Julia (2002), “Residencia posmarital y migración: un estudio de caso de grupos domésticos en el Valle de Solís, Estado de México", Papeles de Población, Nueva época, año 8, núm. 32, México.

Plan Veracruzano de Desarrollo, 1999-2004, Gobierno del Estado de Veracruz, México.

Roberts Kenneth D. (1997), “China's 'Tidal Wave' of Migrant Labor: what Can We Learn From Mexican Undocumented Migrations to the United States?", International Migration Review, núm 31, Georgetown, TX, pp. 2-3.

Robichaux, David (1997), "Un modelo de familia para el México profundo", en Espacios familiares: ámbitos de solidaridad, Departamento de Integración Familiar, DIF, México.

(2002), "El sistema familiar mesoamericano y sus consecuencias demográficas: un régimen demográfico en el México indígena", Papeles de Población, Nueva Época, año 8, núm. 32, México.

Rosenblum, Marc (2002), "Beyond the Policy of no Policy: Emigration from Mexico and Central America Center for Comparative Immigration Studies", Working Papers, University of California, San Diego, ttp://repositories.cdlib.org/ccis/papers/wrkg54

Santiago Cruz, M. de Jesús (2001), “Importancia económica de la migración internacional en México. Análisis desde la perspectiva de las remesas", Momento Económico, núm. 15, México.

Tuirán Rodolfo (2002), "Migración, remesas y desarrollo", en Consejo Nacional de Población, La situación demográfica de México, 2002, Conapo, México.

Unger, Kurt (2005), “Regional Economic Develepment and Mexican Out-migration", Working Paper 11432, National Bureau of Economic Research, Cambridge, MA, http://www.nber.org/ papers/w11432.

Villa, M. y Jorge Martínez Pizarro (2000), “Tendencias y patrones de la migración internacional en América Latina y el Caribe", Población y Desarrollo, Cepal/CELADE/OIM. 
ESTUDIOS FrONTERIZOS, VOL. 10, NÚM. 19, ENERO-JUNIO 2009

Winders, Jamie (2005), "Changing Politics of Race and Region: Latino Migration to the US South", Progress in Human Geography, núm. 29.

Recibido en noviembre de 2007 Segunda versión recibida en agosto de 2008 Aprobado en noviembre de 2008 